\title{
CHEMISTRY
}

\section{МОДИФИЦИРОВАНИЕ КОЛЛАГЕНА И ЖЕЛАТИНА ПОД ДЕЙСТВИЕМ МИКРОВОЛНОВОГО ПОЛЯ}

\author{
Саевич О. В., \\ к. х. н. Украина, г. Днепр, Днепровский национальный университет имени Олеся Гончара \\ Чернушенко О.О. \\ к. х. н. Украина, г. Днепр, Днепровский национальный университет имени Олеся Гончара
}

DOI: https://doi.org/10.31435/rsglobal_ws/30042020/7024

\section{ARTICLE INFO}

Received: 13 February 2020

Accepted: 10 April 2020

Published: 30 April 2020

\section{KEYWORDS}

collagen,

gelatin,

microwave field,

modification,

degree of swelling.

\begin{abstract}
The microwave field influence on the physicochemical properties of collagen and gelatin was studied. It is shown that when microwave field acts on the studied protein samples, a change in the molecules structure formation occurs. It was experimentally established that microwave exposure leads to the structural modification of collagen and gelatin molecules. This modification is accompanied by a change in the physicochemical properties of the studied biopolymers. It is shown that microwave field exposure leads to a decrease in the viscosity of collagen and gelatin solutions. A decrease in viscosity indicates that there's a structural or transient processes occurring in protein molecules.

The kinetics of swelling with time for collagen and gelatin samples was studied. It is shown that the use of a microwave field leads to a decrease in the rate constant of swelling. The swelling degree of the studied samples decreases on average by $60 \%$. It is shown that isoelectric points of the proteins are shifted (pI from 5 to 6 for collagen and up to 5.5 for gelatin).
\end{abstract}

Citation: Саевич O. В., Чернушенко О. О. (2020) Modyfytsyrovanye Kollahena y Zhelatyna pod Deistvyem Mykrovolnovoho Polia. World Science. 4(56), Vol.1. doi: 10.31435/rsglobal_ws/30042020/7024

Copyright: (C) 2020 Саевич О. В., Чернушенко О. О. This is an open-access article distributed under the terms of the Creative Commons Attribution License (CC BY). The use, distribution or reproduction in other forums is permitted, provided the original author(s) or licensor are credited and that the original publication in this journal is cited, in accordance with accepted academic practice. No use, distribution or reproduction is permitted which does not comply with these terms.

Введение. Коллаген и его производная - желатин - природные биополимеры животного происхождения. Они широко применяются в различных отраслях - это основы для лекарственных препаратов - фармацевтики, составляющая косметических средств, пищевых продуктов, фотоматериалов и др. Коллаген и желатин промышленно выпускаются в нескольких формах. Все они характеризуются аналогичной пространственной структурой, которая обусловлена наличием агрегатированных трехспиральных фибрилл, стабилизированных электростатическими, гидрофобными и водородными связями, и обуславливает их основные свойства [1-3].

Производство коллагена и желатина - длительный процесс. Одной из временных стадий является сушка полученного белкового концентрата. При промышленном производстве коллагена и желатина обычно используют сушку фильтрованным сухим воздухом $[4,5]$. Сушка с дополнительным воздействием физических полей (например: микроволновая сушка) является одной из перспективных при производстве продуктов питания. Применение микроволнового (MB) излучения позволяет значительно ускорить время сушки ряда пищевых продуктов $[6,7]$. Однако, воздействие высокоэнергетического микроволнового поля может сопровождаться структурными перестройками в молекулах биополимеров. 
Целью работы является изучение влияния микроволнового поля на физико-химические свойства коллагена и желатина.

Результаты и их обсуждение.

Было исследовано микроволновое воздействие на концентрированные растворы коллагена и желатина. Экспериментальным путем были подобраны приблизительные параметры микроволнового облучения: мощность 800 Вт, суммарное время 21 мин (технологическая схема -3 стадии по 5 мин с интервалом в 3 мин между ними). Режим микроволнового воздействия был подобран таким образом, чтобы не допустить термической деструкции белков. Образцы после проведения микроволновой сушки измельчали на дробильном агрегате, просеивали и перемешивали до однородности. Получали прозрачные кристаллы, визуально идентичные по качественным показателям промышленным образцам.

Для исследования реологических свойств образцов коллагена и желатина готовили рабочие растворы в интервале концентраций $(0,25-2 \%)$ по методике [8]. Для сравнения были приготовлены растворы из промышленных образцов коллагена и желатина аналогичных концентраций. Вискозиметрическим методом с использованием термостатированной ячейки $\left(20^{\circ} \mathrm{C}\right)$ определяли вязкость растворов белков [8]. Экспериментальные данные изменения величин относительной вязкости растворов биополимеров от концентрации представлены на рис. 1:

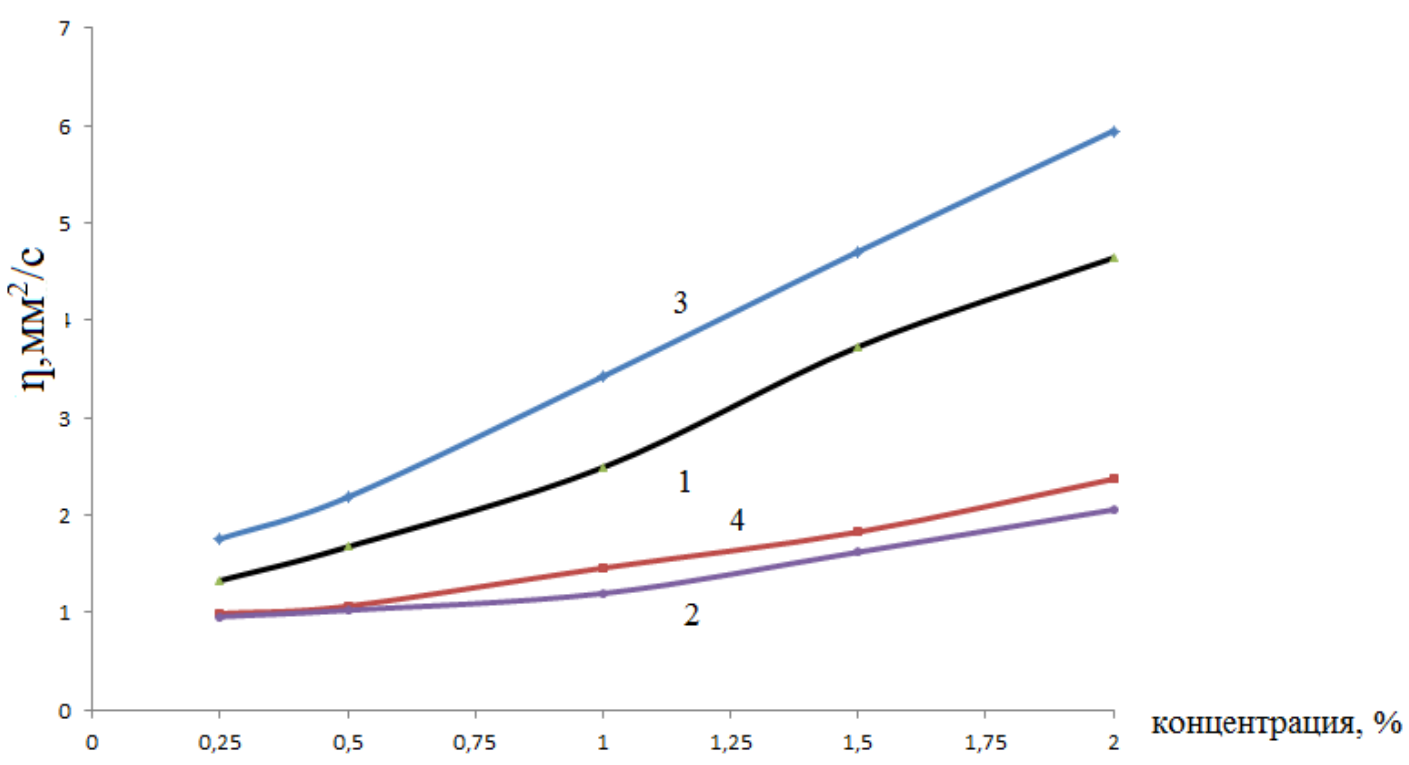

Рис. 1. Зависимость вязкости от кониентрации растворов коллагена и желатина:

1. контрольный образеи коллагена; 2. образеи коллагена облученного микроволновым полем;

3. контрольный образеи желатина; 4. образеи желатина облученного микроволновым полем

Как видно из приведенных данных - воздействие микроволнового поля приводит к значительному уменьшению величины вязкости растворов коллагена и желатина. Вязкость растворов характеризует конфигурацию и размеры молекул белка в растворе и позволяет определить конформационные изменения в строении белков $[9,10]$. Уменьшение вязкости указывает на структурные или переходные процессы, происходящие в молекулах белков. Такие процессы сопровождаются резким уменьшением числа водородных связей вследствие микроволнового воздействия. Известно, что связанная вода, входящая в состав белков, будет первой подвергаться микроволновому воздействию и играть важную роль в структурных изменениях белковых молекул [11]. Изменение величины вязкости при микроволновом облучении свидетельствует о структурных изменениях коллагена и желатина. Средневязкостная молекулярная масса белков была рассчитана по методике [8] и составила для коллагена и желатина 7243 г/моль и 1403 г/моль соответственно. Уменьшение молекулярной массы после микроволнового воздействия до 1506 г/моль для коллагена и 708 г/моль для желатина, подтверждает предположение об изменении структурообразования молекул белка при воздействии микроволнового поля возможно за счет удаления избыточной части гидратационной воды биополимеров. 
Одним из важных эксплуатационных свойств коллагена и желатина, которое также зависит от их пространственного строения, есть степень набухания. Исследовалась кинетика набухания от времени для образцов коллагена и желатина: контрольного и полученного, с применением микроволнового воздействия. Набухание оценивали весовым и объемным методами. Сравнительная характеристика изменения массы поглощённой воды образцами коллагена и желатина приведено на рис.2.

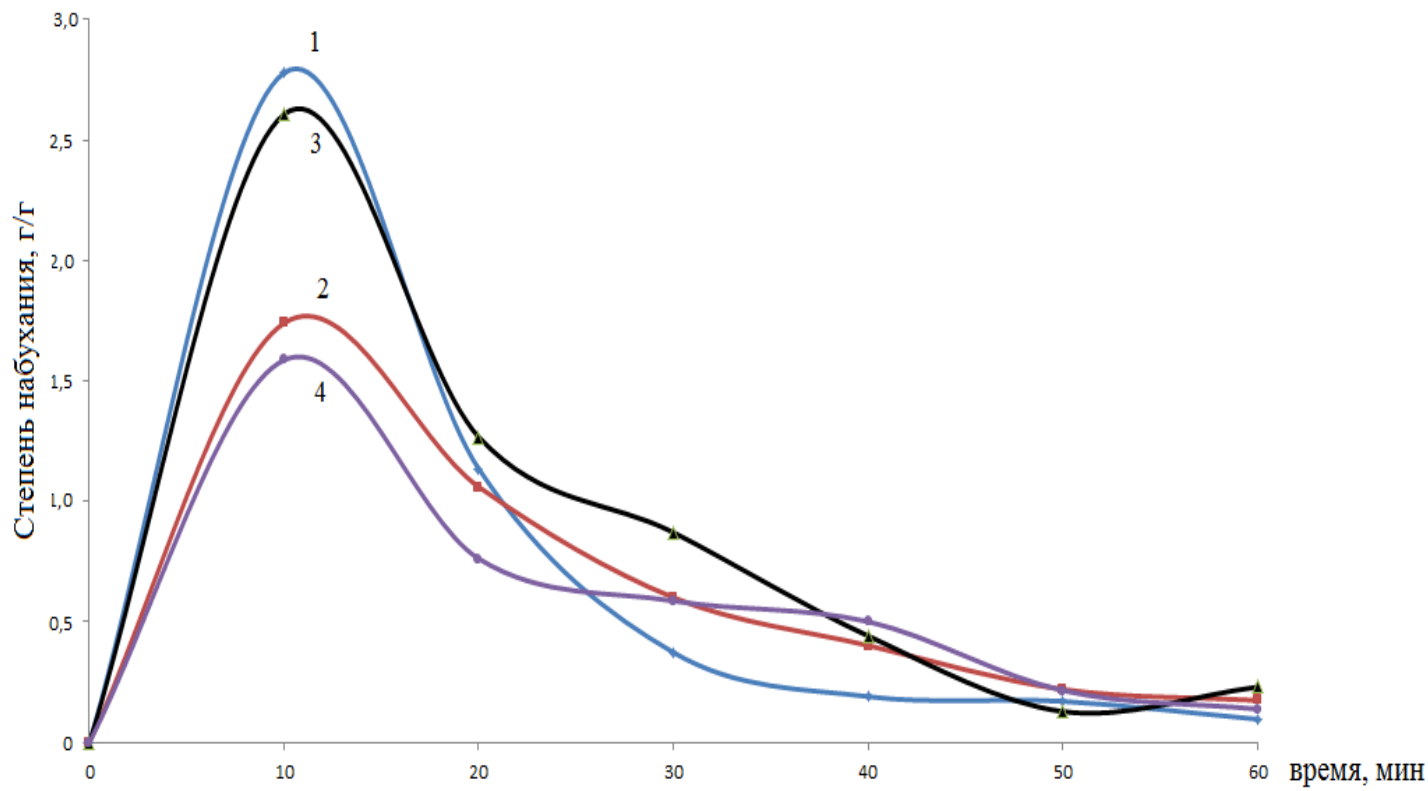

Рис. 2. Зависимость степени набухания коллагена и желатина от времени набухания

1 - контрольный образеи коллагена; 2 - коллаген после микроволнового облучения;

3 - контрольный образец желатина; 4 - желатин после микроволнового облучения.

Графическим методом были определены константы скорости набухания. Показано, что для образцов коллагена максимальное набухание наблюдалось на 10 мин, при этом скорость набухания контрольного образца составила $2,814 \cdot 10^{-3}$, а облученного - 3,204 $\cdot 10^{-3} \mathrm{r} /$ мин. Константа скорости набухания составила 3,84 и 1,17 для контрольного и облученного образцов соответственно. Для образцов желатина максимальное набухание также наблюдалось на 10 минуте, скорость набухания контрольного образца составила $2,79 \cdot 10^{-3}$, а облученного $-1,13 \cdot 10^{-2}$ г/мин. Константа скорости набухания составила 1,61 и 0,88 для контрольного и облученного образцов желатина соответственно. Таким образом, применение микроволнового поля для сушки приводит к уменьшению константы скорости набухания для образцов желатина и коллагена.

При исследовании степени набухания определено, что образцы желатина и коллагена, полученные с использованием микроволнового излучения набухают значительно меньше, чем контрольные. Для образцов коллагена полученные зависимости аналогичны. Степень набухания исследуемых образцов составила для коллагена для облученных и контрольных 760 и $490 \%$, и для желатина 520 и $312 \%$ соответственно. Таким образом, применение микроволнового воздействия приводит к уменьшению степени набухания и коллагена и желатина практически на 60 \%.

Известно, что одной из важнейших характеристик, определяющих равновесное состояние белковых молекул является значение $\mathrm{pH}$ их изоэлектрических точек (pI). Вблизи изоэлектрической точки наиболее эффективно протекает самоупорядочность макромолекул в растворе, которая также сопровождается структурными и конформационными переходами. В работе были определены значения $\mathrm{pI}$ образцов желатина и коллагена до и после применения воздействия МВ-поля. На рис. 3 представлены данные исследования влияния $\mathrm{pH}$ буферных растворов на степень набухания исследуемых образцов. Экстремумы этих зависимостей связаны с минимизацией суммарного поверхностного заряда на молекулах белка и определяют изоэлектрическую точку белка. 


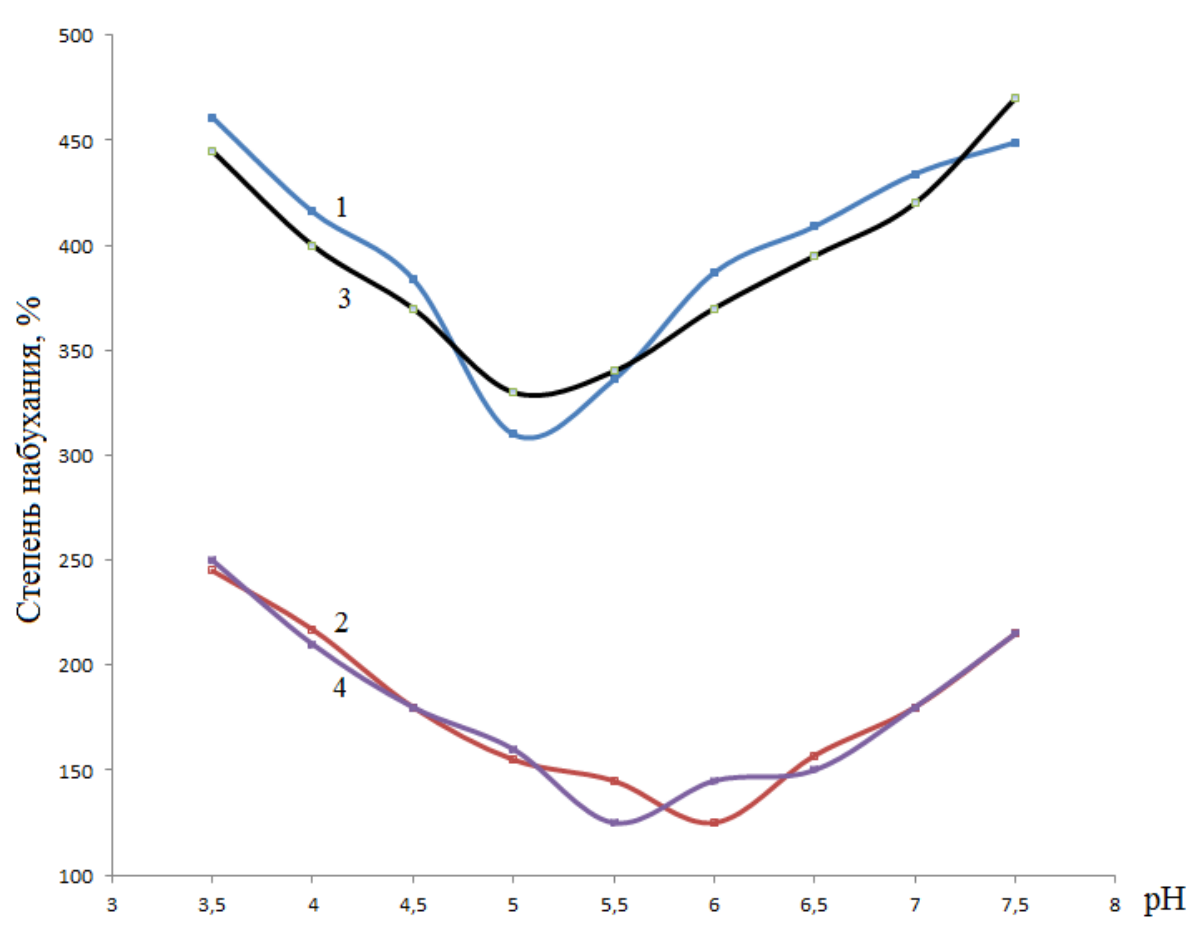

Рис 3. Влияние рН буферного раствора на величину набухания образиов коллагена:

1. контрольный образец коллагена; 2. образец коллагена облученного микроволновым полем

3. контрольный образеи желатина; 4. образеи желатина облученного микроволновым полем

Сравнение данных показывает, что использование микроволнового поля приводит к увеличению значения изоэлектрической точки белков. Для коллагена наблюдается сдвиг изоэлектрической точки с 5 до 6 после проведение микроволнового воздействия, pI образцов желатина также увеличивается до значения 5,5. Изменение значения изоэлектрической точки белков сопровождается их структурной модификацией.

Выводы. Изучено влияния микроволнового поля на физико-химические свойства биополимеров. Показано, что микроволновое воздействие приводит к структурной модификации молекул коллагена и желатина, которая сопровождается изменением физикохимических свойств биополимеров: значительному уменьшению величины вязкости растворов биополимеров; уменьшению степени набухания белков в среднем на $60 \%$; смещению изоэлектрических точек в более щелочную область.

\section{ЛИТЕРАТУРА}

1. Вейс, А. Макромолекулярная химия желатина - М.: Пищ. пром-сть, 1971.478.

2. Зіменковський Б.С., Музиченко В.А. Біоорганічна хімія. - Львів: Кварт. 2009. 402.

3. Михайлов, А. Н. Химия и физика коллагена кожного покрова: монография - М.: Легкая индустрия, 1980. 232.

4. Неклюдов, А.Д., А.Н. Иванкин А.Н. Коллаген: получение, свойства и применение: монография. М.: ГОУ ВПО МГУЛ, 2007. 336.

5. Джафаров, А.Ф. Производство желатина. - М.: Агропромиздат, 1990. 287.

6. Семенов, Г.В. Основы теории, техники и технологи сублимационной сушки - М.: МГАПБ, 2003. 89.

7. Саевич О.В., Чернушенко О.О. Вплив мікрохвильової сушки на структуру желатину. Праці Таврійського державного агротехнологічного університету, 2018, Вип.18, Т1.,167-173.

8. Ганзюк Л.І. Основи хімії і фізики високомолекулярних сполук. Т.1. Загальні положення. Волокноутворюючі полімери. Сучасні методи досліджень полімерів: Навч. посібник. Хмельницький: ТУП, 2002. 235.

9. Драббе А. Практическая химия белка. - М.: Мир, 1989. 623.

10. Завлин П.М., Измайлова В.Н., Сакварелидзе М.А., Ямпольская Г.П. Структура и свойства коллагена источника и предшественника желатины. Журнал прикладной химии (ЖПХ), 1993. Т.66, №2. 320-335.

11. Vandelli, M.-A., M. Romagnoli, A. Monti, M. Gozzi, P. Guerra, F. Rivasi, and F. Forni, Microwave-treated gelatin microspheres as drug delivery system, J. Controlled Release, 2004, Vol. 96, 67-84. 